\title{
Choice Feminism and Adult Worker Model in Neoliberal Era. Some Effects of Inclusive Policies
}

\author{
By Serena Marceno* \\ Alessandra Pera ${ }^{\dagger}$
}

In the last decade, the adult work model has been invoked, both by the EU social reformers and at an international level, to orient their respective policies on feminine work and social inclusion at different levels. Such neoliberal model assumes that feminization of work implies treating women as autonomous individuals free to choose their carrier in the job market or to decide whether to work, to take care of their family or to find time and spaces to conciliate both. In the western legal tradition and policies, the ideological approach of separation between public and private sphere is still dominant, and care has been confined in a private space concealed within the family. At the same time, feminization of paid work has become a synonym for precarious life, which involves both women and young men, and the rhetoric of individual responsibility and empowerment has been combined with harsh stabilization and structural adjustments policies and reduction of social policy. Consequently, a premise grounded on free choice is misleading. Different methodological approaches, both deductive and inductive, will be used in this paper, together with comparative and philosophical insights on statistical data and scholarly writings.

Keywords: Conciliation, Feminization, Precariousness, Subsidiarity Welfare.

\section{Introduction}

This study aims to analyse concepts and practices such as welfare and precarization of feminine work, as well as the effects that can be seen from the empirical point of view in the current context that combines neo-liberal policies and the economic crisis (Cammarata and Marceno 2014).

According to many scholars at the global level, there is a gender issue within the crisis that can be observed through the transformation of the male breadwinner model into a hybrid and precarious adult worker model. The male breadwinner model is that of the traditional nuclear family, with a breadwinner, a male provider who grants the family income, and a housewife. The adult worker model refers conversely to a family model that is no longer the traditional one, in which the roles have changed and both men and women can be - and often are - the providers. The adult worker model disregards gender and individuals are considered as workers, what matters is their agency, their power of choice, and their participation in the labour market is seen as an expression of such ability to choose (Giullari and Lewis 2005, Daly 2011).

\footnotetext{
* Assistant Professor of Human Rights and Political Philosophy, University of Palermo, Italy.

${ }^{\dagger}$ Associate Professor of Comparative Law, University of Palermo, Italy.
} 
In the first part of this study we intend to analyse the crisis of the European welfare systems and the consequent precarization processes $(\$ 2)$. In the second part we will evaluate the effects of these policies on the peculiar position of women in the empirical context of the current crisis and the precariousness of feminine work, in particular in Greece and Italy (§ 3). Finally, in the last part, we will present some concluding reflections on the strategies put in place and its effects and will, also, suggest a proposal that tries to combine the role of policy maker, that the state cannot and must not abandon, with the emerging and formalization of informal welfare, which in the last twenty years of crisis has replaced the formal one $(\S 4)$.

\section{Welfare, Workfare, Debtfare}

Until the end of the 70's, welfare systems in Europe were based on a social protection system, built around the figure of the hired labourer as an anthropological and ontological model of citizenship, in the context of the Fordist industrial capitalism (Esposito 2015).

This model of social production and reproduction of the labour force entailed a form of welfare state which had to deal with: illness, old age, accident, maternity, unemployment (Rosanvallon 1981, Ewald 1986), to which was added a form of domestic welfare, based on care entrusted to women, unpaid and unrecognized (Fraser 2013).

Through a process of recognition and misrecognition the wageworker, who was always breadwinner and male, took on the role of citizen provider, according to the breadwinner model, while the housewife, to whom home care was entrusted, remained excluded from the recognition of a full political and labour subjectivity.

The classic model of the Welfare State, as we know, underwent a crisis in the 70's, together with the Fordist production model, and, since the $80 \mathrm{~s}$, was replaced by the so-called Neoliberal Toyotism. In such scenario, everyone, regardless of gender identity, class and race, is active on the entrepreneurial level, sharing self-responsibility within the more and more individualized, flexible and outsourced production processes. Thus a competitive model was imposed, involving every walk of life and according to the human capital model introduced by neoliberalism at the global level (Marazzi 1999).

The crisis of the Fordist model has produced a transformation in the welfare models, generating a dimension that has been defined as workfare. If in the welfare system the State integrates the subjects supporting them in times of social and economic vulnerability, workfare is based on the entrepreneurial agency of the individual. In other words, the workfare cuts welfare in the form of the donation and supports the vulnerable subjects through job training and retraining programs. What changes is the collectivist model of integration based on citizenship on which the welfare state was grounded, in favour of an individualistic and individualizing model based on the productivity of the individual. It is no longer the population to be the object of government; it is 
rather the individual who governs itself, as human capital, entrepreneur of itself and of the productive potential of its own resources and skills, responsible for its own needs and desires, no longer delegating the State with the satisfaction of its own wellness (Foucault 2004).

This transformation has clearly affected the sovereign dimension of nation-states. In conjunction with some geo-political phenomena that occurred between the 70s and 80s, the United States and Europe have initiated a process of reforms of the labour market and of the social security and pension systems, reducing and privatizing welfare systems and services, globally liberalizing the markets, through the adoption of financial policies more attentive in the reduction of debt and inflation rather than aimed at the growth of the productive system. These processes, undertaken in a political context of neoliberal reforms, led to the phenomenon known as financialisation of the economy, i.e. to a redefinition of the relationship between State and market, and the reconfiguration of government functions of sovereign States that are turned to economic rationality, free market, which have replaced the traditional mechanisms of democratic legitimacy (Brown 2005). Thus, the neoliberal rationality has established itself as a political rationality, by reconfiguring the social pact based on the guarantee of security, and welfare has come out of the sphere of social rights to move within the credit relationships that are established between individuals and a series of state and non-state actors. Such process of financialisation and economic privatization broke the legitimacy and consensus mechanisms based on the assumption of responsibility by the State in satisfying the needs of citizens through welfare systems and has segmented the collective dimension, leaving the individuals with the responsibility of the management of the inequalities of the system.

In neo-liberal societies we are witnessing today the affirmation of subjects committed to assuming their own risks as well as the economic and social consequences of the inequalities in the economic system, and debt operates as a device that directly ties the forms of investment of human capital to both risk management and the increasingly financialised dimension of contemporary capitalism.

We can therefore speak of a real debt ethics that governs the replacement of the traditional welfare through the forms of workfare to get to the forms of the present welfare state as debtfare (Lazzarato 2011).

\section{The Adult Worker Model to the Facts}

The above-described neoliberal economic policies have resulted in a precarization of life that the current economic and financial crisis has reinforced starting from 2008.

According to many scholars we face a feminization of the work process, which is linked with two phenomena: the decline of the male breadwinner model and the birth of an adult-worker model; and, the decline of the welfare 
state and consequential privatization of care services (Ehnreich et al. 2004, Elson 2012.).

As Diane Elson aims, feminization does not mean an increase in women's presence in the labour market but rather that "the labour market conditions of men have deteriorated and become more like the precarious labour market conditions that have typically characterized many 'women's job"' (Elson 2012: 94).

Labour market flexibility, trade liberalization, financial crisis, economic recession, all have extended those conditions of exploitation that were typical of woman's informal job to many male workers, especially young ones, producing a general deterioration in women conditions of work and life in terms of unemployment, wage reduction, precarization, and a reduction of rights concerning social safety and social protection: rights against unfair dismissal, pension rights, health insurance rights, maternity rights.

We are facing an equalization that doesn't imply a gender gap reduction but rather an increase in the limits to women's free choice of employment: "The choices that women make are constrained by the pressure of precariousness, and case studies document the way that neo-liberal policies have forced women to accept whatever paid work they could get, despite deteriorating pay and conditions". (Elson 2012: 94)

In this context, the adult worker model, rather than pointing out an equalizing up, i.e. women's access to full freedom and autonomy in the labour market, is the sign of an equalizing down, that is a manifestation of the processes of precarization of wage and guaranteed work, which also affect the male labour, giving birth to an adult worker, who is not a subject of empowerment, capable and independent, as the neoliberal storytelling would have us believe, but is rather hybrid and precarious.

The 2015 data supplied by Eurostat show us a slow increase in the employment rates for women in southern and central-eastern countries. Large gender gaps are found in Greece ( $48 \%$ circa), Italy (52\% circa), Malta (53\% circa), Romania (58\% circa) and Czech Republic (61\% circa). The highest employment rates for women are recorded in Sweden $(78 \%$ circa) and Germany (74 \%) (Eurostat n.d.).

The presumed reduction of the gender gap in European employment levels, a fact that - as we have seen - is very heterogeneous with respect to domestic situations, as in the case of Italy and Greece, hides two important phenomena. On the one hand, the reduction of the gap is caused more by the increase in male unemployment than by a rise in female employment levels, and is therefore a clear example of equalizing down (Karamessini and Rubery 2013, Bettio et al. 2012). On the other hand, we are facing a concealment of the real costs incurred by women due to the lowering of wages and the cut to welfare services. 
Figure 1. Employment Rates by Sex, Age, and Citizenship (\%) 2016

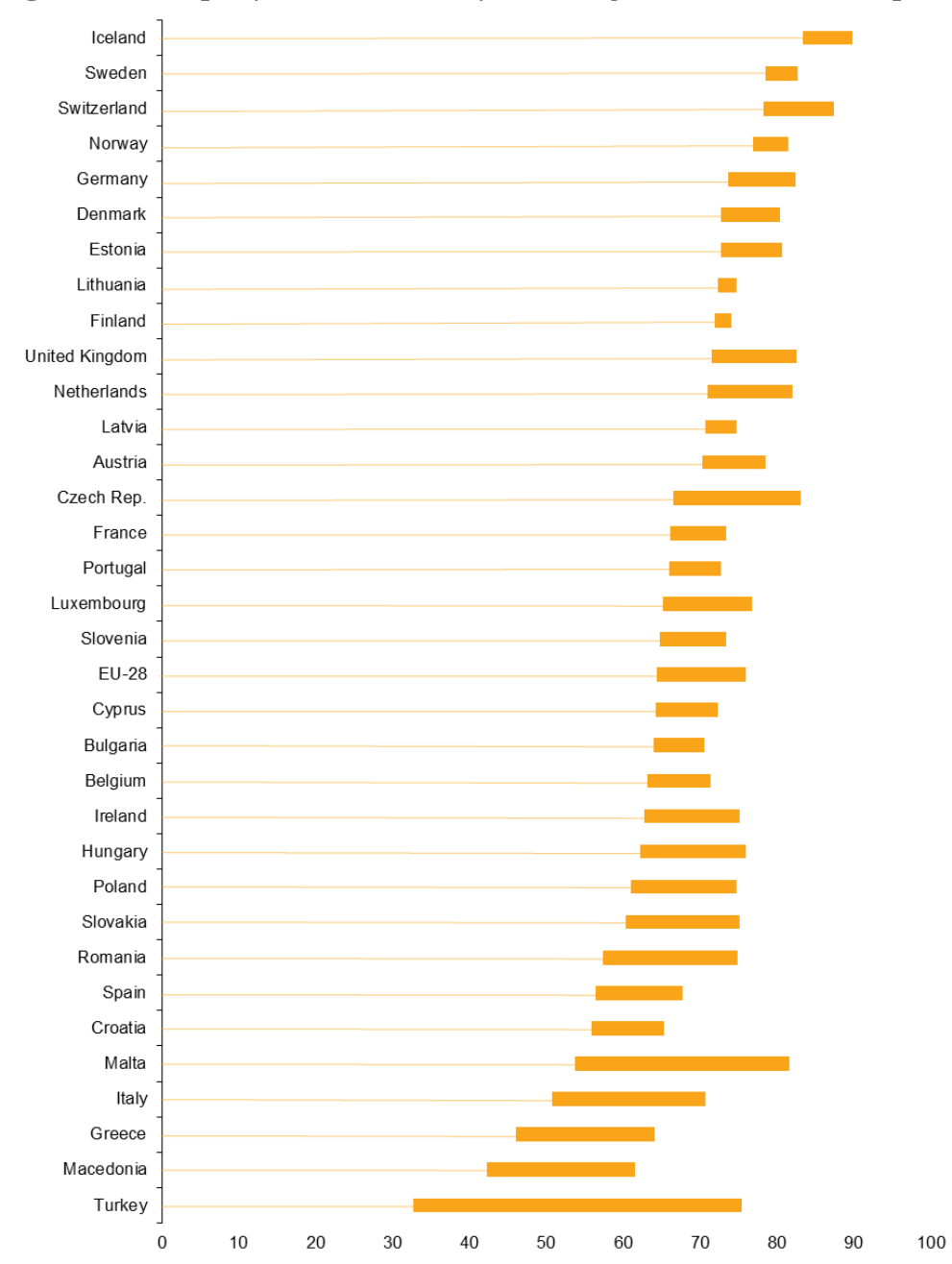

Source: Eurostat n.d.

The current crisis is making the effects of neoliberal recipes more pervasive, aggravating the traditional vulnerability of women in the labour market, and extending it in fact also to men. Consider in particular the reform of the pension system (different retirement age according to gender), the reductions of subsidies/grants/facilities for the care of people, or even to the increases in tariffs for subsidized public services. Moreover, this situation is producing a hiding effect of the issues of gender inequality, which have disappeared from the political agenda, as if it were problems that one can afford to deal with only in times of economic prosperity (Walby 2009).

In Italy, the status of women over the last twenty years has changed due to the deregulation of the labour market and the welfare contraction. The link between job flexibility and economic growth has been widely refuted on the basis of the available empirical data, which show that to the decline of employment social protection indices corresponds a growth of both the primary inequalities and the inequalities in the disposable income. 
The high inactivity rate of Italian women is justified by the factors that make it difficult to combine care work and work for the market: the inadequacy of the offer of services for children and the elderly, the low family work sharing between spouses (Saraceno 1980), the characteristics of the production system and of the institutions that regulate the labour market and economic activities (Reyneri 2011) and the scarcity of part-time employment opportunities.

The inactivity rate of Italian women, as well as those of Greece, not only does not decrease but begins to involve even unexpected components of the female population (e.g. young graduates), and also includes subjects that are actually active but inside the informal economy, domestic and submerged. Such inactivity is the result of a datum that combines unfavourable conditions on the professional level, a particular view of the role of the wife/mother within the married couple and a great importance given to family welfare and education of children (Fouquet 2004).

The latest available data on the employment situation of Italian women show unemployment rates of $47 \%$ or so. The intensity and persistence of the economic crisis, and the progressive weakening of social protection systems, have expanded the area of poverty and material deprivation, extending it even to population groups previously less affected by economic hardship.

In Italy there is a gender issue related to the entry and stay in the labour market, and to the existence of inequality in pay, career opportunities, the achievement of top positions and difficulties for female entrepreneurs. Women and men participate differently in the labour market, both in quantitative and in qualitative terms and experience a contractual and pension inequality (Villa 2013).

In the market of feminine work in Italy there is a certain ambivalence about the effects of deregulation. Since the nineties women have been collectively more active in the job market, but, compared to men, they have been more affected by phenomena of precarization. They have had greater access to informal work or contracts, which did not provide the system of social safety nets, and have suffered from a sharp fall in their expectations about retirement.

The austerity policies resulted in a mode of entry of women into the labour market, which strengthened the gender gap, worsening their real social negotiation skills. In fact, the more women are put in a condition of marginalization from the sphere of real economy (if not in the forms of precarization) the more they disappear from the public sphere, they lose voice, are driven back into the stereotype (of care, of the limited nature of their economic contribution to the family budget).

In fact, both Greece and Italy are strongly connoted by the mononuclear family model from a cultural point of view.

Not by chance, recently, Greek literature has underlined that the role played by women in the crisis scenario affects also individuals' responses, which can go into two different directions: 1) retreat home and become invisible, as unpaid carers or as free labour in family firms; 2) seek for more 
work thus generating, as a consequence, the demand for other women to provide care services. In the first hypothesis the cash shortage of the informal welfare would be even worsened. In the second option the result would be the generation of more cash income for the family.

So we have to concentrate on both policy governance and managing but also on the possible individual choices. These two signs are already both present in the above-mentioned country. For example, the Greek pension reform (law 3368/10) has increased women retirement age and has determined an exodus of female workers from banks and public services, but at the same time women seem to look for second and added works. This happens even though they encounter many obstacles in legislation protecting incumbents and not promoting flexible forms of employment (Lyberaki and Tinios 2014).

\section{Revisiting Subsidiarity: A Hybrid Model}

We have analysed statistical data of different Countries, which are the expression of heterogeneous social and economic backgrounds, where female work and, more in general, the job market conditions are dissimilar. It is impossible to suggest solutions giving a "receipt good for every place".

Not by chance, in the last decades EU interventions through the ESF have been oriented by subsidiarity, in order to ensure that every change, reform or improvement attempt all consider the real and effective needs of local communities as premises.

This approach presumes that all the actors of the implemented policy behave virtuously, but we must take in account the (in)capacity of individual local realities to create instruments and implement policies governing the conciliation processes.

Such realities, which are weaker in managing and governing conciliation policies, should lead to a reconsideration of subsidiarity and the consequent functional decentralization.

If empowerment is the premise of the "effective choice" of the adult worker model (which we are reconsidering in a critical way), and if freedom of choice means to have many options and to select the one that fits better with the worker/family needs, the duty of public authority - and of the legal system in its whole - is to create the conditions for such choice, for the above mentioned possible options.

Through regulatory action, the legal system should provide for detailed guidelines and rules, budget constraints and specific settled and determined instruments, which respond to policy objectives and guide the operator's choice in a gradually increasing system, making it basically more and more close to the best general model among those submitted.

In the model we are suggesting, in other words, the actors of the job market (mainly public bodies and companies, owners, farmers, employers) are able to choose welfare and conciliation measures that they are capable or interested to offer to workers. At a public level, the achievement of the 
objectives could be encouraged through rewarding measures in favour of those actors (public or private, institutional and para-institutional and/or third sector, employer and employee), who carry out behaviours of virtuous compliance towards the model.

According to existing specialized literature (Pettit 1996, 1997, 2002), a complier centred institutional design strategy starts from the premise that human individuals are neither virtuous nor wicked. It assumes people as generally motivated to comply and cooperate, even if they are corruptible. These strategies consist in applying sanctions in a plainly encouraging way. They should be primarily directed to compliers but, at the same time, they should provide sanctions against wrongdoing if the addressees do not comply or abuse or misuse the awards or the procedural way to achieve the awards.

Of course, no institutional design applied in real life would result in a perfect degree of compliance, but there are various kinds of measures that can be taken to achieve a good level of compliance.

A Consolidation of legislation in the area of welfare and workfare can be a solution in order to systematize the existing legislation and to specify new conciliation programs, involving public institutions at different levels and the actors of the working relationship (employer-employee) and the ones of the third sector (public and private), who offer services related to conciliation.

As said above, the main problem is that due to the cost of conciliation, welfare and workfare measures the culture of conciliation is not widely spread because it is perceived as expensive. Costs quite often weigh on medium and small business, so, in order to go beyond many resistances, the legislative intervention cannot consist in the provision of fixed and strict rules backed by sanctions and punishments from which to escape.

The introduction, proposition and support to devices of this kind - at the level of state legislation, in the exercise of the function of political address can be operated through different paths: the use of money and economic incentives (tax rebates, bonuses, incentives) for virtuous companies or the most active actors of the third sector, which provide the market with the services listed below on a local basis; bargaining between the social partners; the involvement of the third sector and families; an original combinations of some or all of these routes.

As in other areas of law, characterized by the necessity to promote different and sometime contrasting values and interests, the public intervention, in terms of legislative policy, should be a balanced choice of measures of regulation, deregulation and prohibition/reward, which embolden all the above described actors to make use of such instruments because it is expedient and convenient, money saving and suitable for the company, firm, institution etc.

The idea is, for those who accept to bear the immediate economic cost of welfare and workfare measures, to prospect the concession of benefits in terms of general interests that go beyond the mere profit of the enterprises. Costs will be suffered at the first stage by the private sector, but, at the end, they will arise at a public level in terms of less income from taxes, pensions and services. 
The legislative power in the EU legal systems should provide a virtuous model on increasing levels, each of which gradually implements multipliers or various combinations of "conciliation measures", identifying benefits for each level prospected to reward those who concretely adopt such suggested instrument.

The main areas of intervention, already identified in a recent study (Pera and Nicolosi 2015), could be:

a. Income support instruments: benefit plans (insurance policies for hospital charges and high diagnosis, for accidents, public transport costs, redemption of nursery and kindergarten fees, babysitting, domestic workers and caregivers, redemption of school and sports fees); integration of the maternity allowance; supplementary pension; real estate loans; loans; subscriptions.

b. Flexible instruments concerning working conditions: part-time, to be renegotiated every year under the workload and family organization; bank of hours; abolition of badging procedures with wide in-and-out flexibility and attendance software; classic and customized teleworking.

c. Services of conciliation of life and working times: kindergartens; canteen; shuttle-bus and mobility plans; company doctor; time-saving services (company laundry, handling of tickets for cultural events, summer camp and recreational measures for children, care services for the house and for the person).

d. Parent program: a set of projects in support of the manager in the management of the motherhood of the employee and of the same employee during the absence or in the phase of the return to work, after the abstention.

e. Company auditing services: psychological, career, and conciliation counselling, study permits.

Many of these services could be offered through specific agreements stipulated between the employer/firm/trade union and insurance companies or public/private transport companies. With such "private agreements", on one side, the employee provides those who will offer the service with a number of future contractors; on the other side, the supplier will offer its service at a special price, which will be reduced in consideration of the numerous single sub-contracting parties (single individual, families, de facto couple, entities of various nature).

Among the main part of the legal systems investigated and, in particular, in Italy and Greece the economy is composed by small and medium sized enterprises, so that corporate welfare devices are activated almost entirely on a voluntary basis perhaps not always in a satisfactory way, also due to the lack or the inadequacy of a certain type of management culture. However, sensitivity towards these issues is also still lacking in trade unions and civil society and in the third sector actors. 
Therefore, it would be useful to institutionalize some conciliation programs, choosing between these indications according to the different context of each member State and of each local dimension, as welfare needs are not the same.

Every company, firm, factory can choose some of those instruments in order to create a package for its workers and every individual, family, couple, etc., can discuss and choose which services and instruments better fit the family needs in order to conciliate private spaces and places and those of work.

This model offers infinite possibilities, and not only that of traditional welfare, but it could be implemented at the maximum ideal level as a multitasking system of services for both single individuals and families, set on the choices of families and of breadwinners. But its limit consists on its tight link to job/work relationship. It assumes a pre-existing job, as the employeeworker being an insider in the job market can choose services and options offered by the employer (small-medium-large firm, trade unions in agreement with insurance companies or other actors) in the above-mentioned menu.

To overtake this limit, and in order to answer to the welfare demand of those citizens that we can call outsiders (of the job market), the necessity arises anyway of public efforts, which can be organized in coordination with third sector actors, who can offer those service on the market in partnership with local autonomies and municipalities.

In any case the system (for insiders) has to be built, in terms of options (alternative or cumulative) on its whole by the legislation, which cannot abdicate its institutional role of policy maker, in order to plan and direct the welfare choices and to individuate the awarding and compliance measures to promote the stakeholders action.

As far as outsider and, more in general, the public active intervention are concerned, Greek literature has underlined the need for a recalibration of the formal welfare system, widening the tax base and equalising expenditure reforms, concentrating on the poorest segment of population. In particular, these authors suggest that: "micro-credit or micro-insurance could directly aid self-employment and small business, rather than simply seeing small-scale entrepreneurship as a source of tax evasion. Perhaps more importantly, the removal of disincentives and other obstacles to employment that currently prevent greater activation by women would allow the operation of an important 'automatic' corrective mechanism. Reform of the most glaring inequities of the formal system could boost the limited links between the receipt of formal transfers and the meeting of needs by the family. To be able to respond intelligently to such challenges, policy needs to supplement administrative data (which by definition can only discern formal processes) with survey data capable of bringing the condition of the informal system to the attention of social policy stakeholders" (Lyberaki and Tinios 2014: 204).

Without any conceit, the model proposed here would be one of the possible answers, of course improvable and perfectible, to the challenge for contemporary (welfare?) States, coming from the need, shared both in Greece and Italy, of an equilibrate combination of social integration and adequate 
public funded social policy, trying to obtain the emersion of informal welfare, turn it into formal and strengthen the previous formal one.

\section{References}

Bettio F, Corsi M, D'Ippoliti C, Lyberaki A, Samek Lodovici Manuela, Verashchaginaet A (2012) The impact of the economic crisis on the situation of women and men and on gender equality policies. Luxembourg: European Commission. Publication Office of the European Union. Retrieved from http://bit.ly/2fLNhye.

Brown W (2005) Edgework: Critical essays in knowledge and politics. Princeton: Princeton University Press.

Cammarata V, Marceno S (2014) Narrazioni di genere e biopolitiche neoliberali [Gender narrative and neoliberal policies]. Milano: Mimesis.

Daly M (2011) What adult worker model? A Critical look at recent social policy reform in Europe from a gender and family perspective. Social Politics 18(1): 1-23.

Esposito M (2015) Politiche di salvezza. Teologia economica e secolarizzazione nel governo del sociale [Salvation Policies. Economic theology and secularization in the government of society]. Milano: Mimesis.

Ehrenreich B, Russel Hochschild A (2004) Global woman: Nannies, maids, and sex workers in the new economy. New York: Henry Holt.

Elson E (2012) Gender justice, human rights, and neo-liberal economic policies. In Gender Justice, Development, and Rights, M Molyneux, S Razavi (eds). Oxford: Oxford University Press.

Eurostat (n.d.) Employment rates and Europe 2020 national targets statistic explained. http://bit.ly/1NFngPS.

Ewald F (1986) L'état providence [The welfare state]. Paris: Édition Grasset,.

Fraser N (2013) Fortune of feminism. From state-managed capitalism to neoliberal crisis. London-New York: Verso.

Foucault M (2004) Naissance de la biopolitique. Cours au Collège de France (19781979) [The birth of biopolitics. Courses at the Collège de France (1978-1979)]. Paris: Gallimard Seuil.

Fouquet A (2004) L'invention de l'inactivité [The invention of inactivity]. Travail, Genre, Societé 1(11): 47-62.

Giullari S, Lewis J (2005) The adult worker model family, gender equality and care. The Search for new policy principles, and the possibilities and problems of a capabilities approach. Geneva: United Nations Research Institute for Social Development.

Karamessini M, Rubery J (2013) Women and austerity. The Economic crisis and the future for gender equality. London: Routledge.

Lazzarato M (2011) La fabbrica dell'uomo indebitato [The making of indebted man]. Roma: DeriveApprodi.

Lyberaki A, Tinios P (2014) The informal welfare state and the family: invisible actors in the greek drama. Political Studies Review 12(February): 193-208.

Marazzi C (1999) Il posto dei calzini. La svolta linguistica dell'economia e i suoi effetti sulla politica [Capital and Affects. The politics of the language economy]. Torino: Bollati Boringhieri.

Pera A, Nicolosi M (2015) Right for conciliation and family welfare. Opinio Juris in Comparatione I(1): 1-23. 
Pettit P (1996) Institutional Design and Rational Choice. In The Theory of Institutional Design, R Goodin (ed), 54-89. Cambridge: Cambridge University Press.

Pettit P (1997) Republicanism: a theory of freedom and government. Oxford: Claredon.

Pettit P (2002) Rationale choice regulation: Two strategies. In Rules, Reasons and Norms: Selected Papers, P Pettit (ed). Oxford: Oxford University Press.

Reyneri E (2011) Sociologia del mercato del lavoro [Sociology of the work market]. Bologna: il Mulino.

Rosanvallon P (1981) La crise de l'État Providence [The crisis of the welfare state]. Paris: Seuil.

Saraceno C (1980) Il lavoro mal diviso [Bad division of work]. Bari: De Donato.

Villa P (2013) Indicatori complementari al tasso di disoccupazione [Complementary Indicators of disemployment rate]. Ingenere $(30 \mathrm{Apr})$. Retrieved from http://bit.ly/2fCJqG1.

Walby S (2009) Gender and the financial crisis. Paper for UNESCO Project on "Gender and the Financial Crisis". Retrieved from http://bit.ly/2g4Vnms. 